\title{
CHILE, COLOMBIA Y ECUADOR: EDUCACIÓN SEXUAL EN CONVENCIONES INTERNACIONALES E INICIATIVAS ESTATALES
}

Diogo Cavazotti Aires

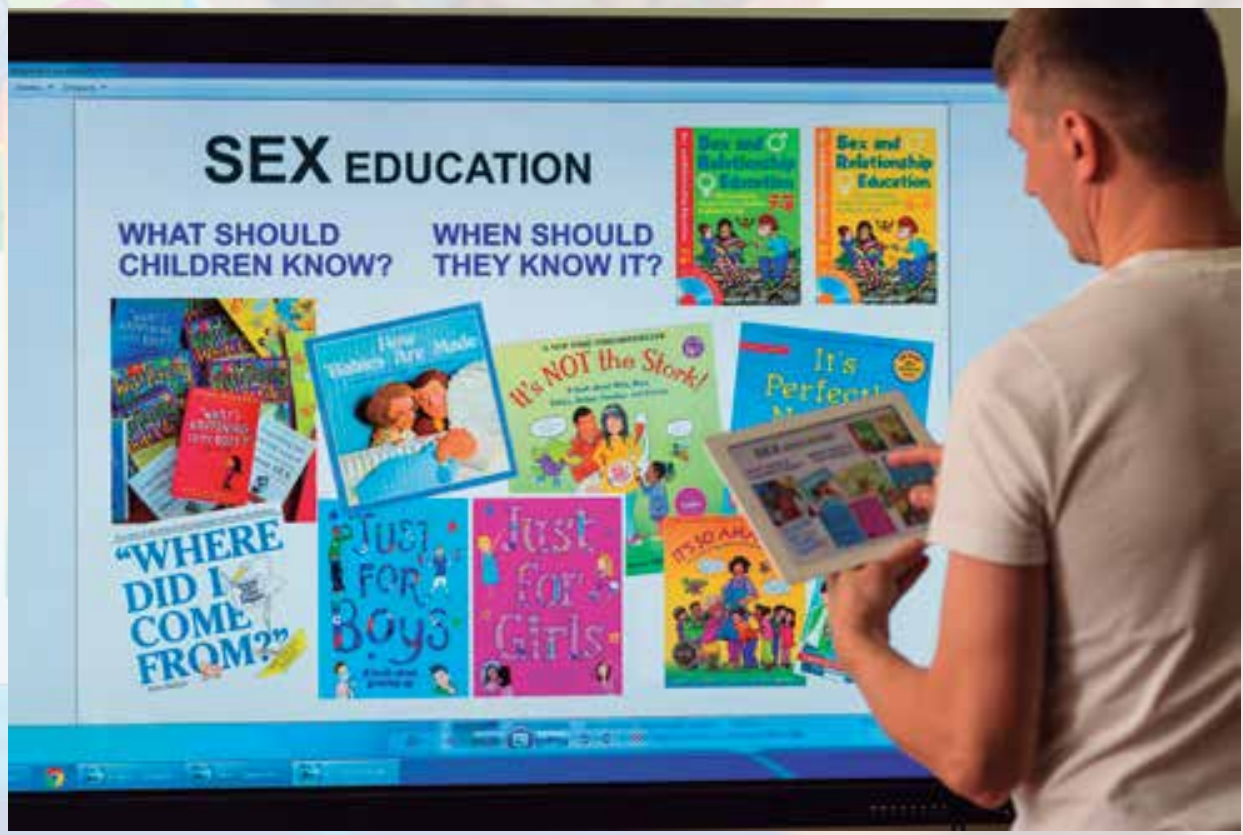





\title{
CHILE, COLOMBIA Y ECUADOR: EDUCACIÓN SEXUAL EN CONVENCIONES INTERNACIONALES E INICIATIVAS ESTATALES
}

\author{
Diogo Cavazotti Aires \\ Universidad Católica de Colombia
}

\section{Resumen}

A partir de la Declaración universal de derechos humanos hasta documentos más recientes del mismo segmento, la educación ha sido tratada como una prioridad en la infancia y la adolescencia, con el objetivo de promover el desarrollo de la personalidad. Esto incluye — a veces, directamente; a veces, indirectamente - la atención a la enseñanza de la sexualidad para mejorar las condiciones y el acceso a la salud pública y al crecimiento personal, profesional y económico del individuo y del país. Con base en las leyes nacionales vigentes, esta investigación explica cómo Chile, Colombia y Ecuador han abordado la educación sexual. El propósito es examinar si estos países siguen los parámetros definidos en convenciones internacionales. La investigación se sustenta en un proceso de revisión y análisis documental que, fundamentado en las recomendaciones de tratados de derechos humanos, indaga sobre la realidad de los países mencionados en materia de educación sexual. En este estudio se logra determinar que los enfoques de educación sexual en Chile, Colombia y Ecuador, que ocupan posiciones distintas en la lista de embarazo adolescente en América Latina, explican los resultados desiguales que presentan dichos países.

Palabras clave: educación sexual, convenciones internacionales, educación, derechos humanos, Chile, Colombia, Ecuador.

El autor: Doctorando en Educación en la Universidade do Estado de Santa Catarina (Udesc/Brasil). Magíster en Derechos Humanos y Derecho Internacional Humanitário en la Universidad Católica de Colombia (UCATOLICA), Especialización en Educación en Derechos Humanos por la Universidade Federal do ABC (UFACB/Brasil). Periodista por la Universidade Tuiuti do Paraná (UTP/Brasil). Correo electrónico:dcavazotti@gmail.com

Recibido: 25 de febrero de 2021; evaluado: 16 de marzo de 2021; aceptado: 02 de mayo de 2021. 


\title{
CHILE, COLOMBIA AND ECUADOR: SEX EDUCATION IN INTERNATIONAL CONVENTIONS AND STATE INITIATIVES
}

\author{
Diogo Cavazotti Aires \\ Universidad Católica de Colombia
}

\begin{abstract}
From the Universal Declaration of Human Rights to more recent documents of the same kind, education has been treated as a priority in childhood and adolescence to promote the development of the human being's integral personality. This includes - sometimes directly, sometimes indirectly - attention to the teaching of sexuality to improve conditions and access to public health and the personal, professional, and economic growth of the individual and the country. This research explains how Chile, Colombia, and Ecuador have approached sexuality education based on current national laws. The purpose is to analyze whether these countries follow the parameters defined in international conventions. The research is grounded on a documentary review and analysis process that, based on the recommendations of human rights treaties, explores the reality of the aforementioned countries in terms of sex education. This study concluded that the different approaches to sex education in Chile, Colombia, and Ecuador, which occupy different positions in the ranking of teenage pregnancy in Latin America, explain the unequal results presented by these countries.
\end{abstract}

Keywords: Sex education, international deals, education, human rights, Chile, Colombia, Ecuador.

The author: PhD student in Education at Universidade do Estado de Santa Catarina (Udesc/Brazil). Master in Human Rights and International Humanitarian Law from Universidad Católica de Colombia, advanced degree in Human Rights Education from Universidade Federal do ABC (UFACB/Brazil). Journalist from Universidade Tuiuti do Paraná (UTP/Brazil). E-mail: dcavazotti@gmail.com

Received: February 25, 2021; evaluated: March 16, 2021; accepted: May 02, 2021. 


\title{
CHILE, COLÔMBIA E EQUADOR: EDUCAÇÃO SEXUAL EM CONVENÇÕES INTERNACIONAIS E INICIATIVAS ESTATAIS
}

\author{
Diogo Cavazotti Aires \\ Universidad Católica de Colombia
}

\section{Resumo}

Desde a Declaração Universal de Direitos Humanos até documentos mais recentes do mesmo âmbito, a educação vem sendo tratada como prioridade na infância e na adolescência, a fim de promover o desenvolvimento da personalidade. Isso inclui — às vezes de forma direta, às vezes, indireta - a atenção ao ensino da sexualidade para melhorar as condições e o acesso à saúde público e ao crescimento pessoal, profissional e econômico do indivíduo e do país. Com base nas leis nacionais vigentes, esta pesquisa explica como Chile, Colômbia e Equador vêm abordando a educação sexual. O objetivo é avaliar se esses países seguem os parâmetros definidos pelas convenções internacionais. Esta pesquisa está apoiada num processo de revisão e análise documental que, fundamentado nas recomendações de tratados de direitos humanos, questiona a realidade dos países mencionados em matéria de educação sexual. Neste estudo, consegue-se determinar que as abordagens de educação sexual nesses países, os quais estão em posições diferentes na lista de gestação na adolescência na América Latina, explicam os resultados desiguais neles encontrados.

Palavras-chave: educação sexual, convenções internacionais, educação, direitos humanos, Chile, Colômbia, Equador.

O autor: Doutorando em Educação pela Universidade do Estado de Santa Catarina (Udesc/Brasil). Mestre em Direitos Humanos e Direito Internacional Humanitário pela Universidade Católica da Colômbia, pós-graduação em Educação em Direitos Humanos pela Universidade Federal do ABC (UFACB/Brasil). Jornalista da Universidade Tuiuti do Paraná (UTP/Brasil). Correio eletrônico: dcavazotti@gmail.com

Recebido: 25 de fevereiro de 2021; avaliado: 16 de março de 2021; aceito: 02 de maio de 2021. 


\section{Introducción}

Según el informe del Fondo de Población de las Naciones Unidas, ${ }^{1}$ América Latina y el Caribe tienen el segundo mayor número de jóvenes entre 15 y 19 años embarazadas (62 casos por cada 1000), solo superados por África (103,5 casos). Dentro de América Latina, las posiciones en la lista fluctúan ampliamente. Si bien tenemos a Chile con una tasa de fecundidad adolescente de 41 en el grupo de edad y selección citados, es decir, inferior al índice continental, Ecuador obtiene el más alto número, con 111 casos. Colombia ha alcanzado un índice de 75 episodios de embarazo por cada 1000 adolescentes, o sea, está lejos de acercarse a Ecuador, pero todavía está por encima del promedio latino. Los datos se publicaron en 2018 sobre la base del análisis realizado entre 2006 y 2015 . $^{2}$

Este estudio analiza las leyes de educación sexual vigentes en Chile, Colombia y Ecuador, de acuerdo con las directrices de las convenciones internacionales de derechos humanos, una vez que la enseñanza en sexualidad aparece con cada vez más frecuencia en estos instrumentos. El criterio de selección para la elección de estos países fue el ranking de índice de embarazo adolescente en América Latina. ${ }^{3}$ La investigación consiste en ampliar el debate sobre cómo los países proporcionan acceso a la educación sexual, una vez que "los derechos sexuales y reproductivos son parte de los derechos humanos y están protegidos por el derecho internacional”. ${ }^{4}$

El análisis de los documentos sobre derechos humanos parte del referente de la creación de la Organización de Naciones Unidas (ONU) y, en consecuencia, la Declaración universal de los derechos humanos. Talavera ${ }^{5}$ escribe que, después de 1945, la humanidad estaba "aparentemente madura" en relación con la toma de decisiones políticas y el pensamiento legal, para aceptar que la protección de los derechos fundamentales de la población era responsabilidad de los Estados

Fondo de Población de las Naciones Unidas [Unfpa], "El impacto socioeconómico del embarazo en la adolescencia representa 1242 millones de dólares o 0,35 \% del PIB anual para seis países de América Latina", http://lac.unfpa.org/es/news/el-impacto-socioecon\%C3\%B3mico-del-embarazo-en-la-adolescenciarepresenta-1242-millones-de-d\%C3\%B3lares-o (acceso noviembre 15, 2020).

2 Fondo de Población de las Naciones Unidas [Unfpa], El poder de decidir. Derechos reproductivos y transición demográfica (Nueva York: Autor, 2018), 132-137.

3 Unfpa. El poder, 132-137.

4 Claudia Liliana Bedoya Abella, "Educación para la sexualidad y construcción de ciudadanía", Sophia 10, núm. 1 (2014): 95, https://www.redalyc.org/pdf/4137/413734078009.pdf (acceso mayol, 2021).

5 Fabián Novak Talavera, "La Declaración universal de derechos humanos cincuenta años después", Agenda Internacional 4, núm. 10 (1998): 77, http://revistas.pucp.edu.pe/index.php/agendainternacional/article/ view/7194 (acceso mayo 12, 2020). 
soberanos; por lo tanto, estos deberían estar en concordancia con el formato de la ONU y las convenciones internacionales tal como las conocemos hoy.

La evolución de este discurso aborda, de manera cada vez más frecuente, los temas sobre educación y sexualidad. Sin embargo, el reconocimiento de la sexualidad como parte fundamental de la educación integral del ciudadano es un gran desafío, sobre todo debido a una resistencia histórica de los Estados. Para Astudillo, ${ }^{6}$ la complejidad de abordar este tema radica en el fracaso de los propios Estados para regular la sexualidad humana por medio de la educación.

En el campo educativo el déficit democrático es grande en oportunidades, en cobertura, discriminación de género y en el hecho de negar o guardar información respecto a la sexualidad, razón por la cual en nuestro continente americano la educación sexual sólo por excepción ha sido incluida de manera formal en los programas escolares oficiales, no obstante reconocerse que es una educación para la vida, la vida real de cada una/o de los educandos; de igual forma a pesar de su carácter de tipo preventivo, formador y que potencia el desarrollo humano. ${ }^{\top}$

Por esta dificultad, los organismos de derechos humanos pasaron, en las últimas décadas, a prestar más atención a este asunto en convenciones internacionales y su importancia en el ámbito educacional, estratégico y, claro, de derechos humanos, como será presentado más adelante.

\section{Metodología}

El análisis descriptivo se llevó a cabo mediante el cruce de datos con base en los documentos de las convenciones internacionales de derechos humanos y las leyes vigentes en los tres países objeto de estudio. Con base en la indagación de fuentes primarias y secundarias, se establecieron los cimientos que ubican la educación sexual en un lugar especial dentro del campo de los derechos humanos. Así, con enfoque cualitativo, el estudio plantea aspectos constitucionales y jurídicos que ponen a estos países de acuerdo o en desacuerdo con las recomendaciones de los organismos internacionales de derechos humanos.

6 María Nelcy Muñoz Astudillo, "La educación sexual en Latinoamérica: un campo de fuerzas en tensión", Cultura del cuidado 14, núm. 1 (2017): 65, https://doi.org/10.18041/1794-5232/cultrua.2017v14n1.4329 (acceso noviembre 27, 2020).

7 María Ladi Londoño, Derechos sexuales y reproductivos: los más humanos de todos los derechos (Cali: Iseder, 1996), 232. 
La elección de un análisis documental de Chile, Colombia y Ecuador tuvo como objetivo hacer una comparación entre estos países ubicados en el mismo continente que ocupan espacios tan distintos en la clasificación del número de adolescentes embarazadas. Según los autores revisados en este documento, esta clasificación es uno de los índices para medir los conocimientos sobre sexualidad proporcionados a los jóvenes por medio de la educación.

La revisión de la literatura reúne autores de diferentes áreas del conocimiento, con el fin de mostrar que la educación sexual es transdisciplinaria, es decir, tiene diversos campos involucrados. Se buscaron puntos de referencia en estudios de psicología, educación, sexualidad y derechos humanos.

\section{Beneficios de la educación sexual}

La Organización de las Naciones Unidas para la Educación, la Ciencia y la Cultura (Unesco) ha considerado la educación sexual como una forma para que niños, niñas y adolescentes reciban información conducente a la toma de decisiones responsables tanto en aspectos de sexualidad como de relaciones interpersonales:

O dejamos a los niños y niñas encontrar su propio camino en la nebulosa de información parcial, la desinformación y la explotación que podrían encontrar en los medios de comunicación, Internet, grupos de pares o personas inescrupulosas o aceptamos la tarea de proporcionar una educación en sexualidad clara, informada, sustentada en hechos científicos e inspirada en los valores universales de respeto y derechos humanos. ${ }^{8}$

En el informe titulado Orientaciones técnicas internacionales sobre educación en sexualidad hay un enfoque basado en evidencias de escuelas, maestros y educadores de salud, el cual aborda un programa de sexualidad para estudiantes entre 5 y 18 años. El documento muestra que la educación sexual es un elemento fundamental para prevenir las infecciones de transmisión sexual (ITS), reducir los episodios de embarazo adolescente, retrasar el inicio de la vida sexual, disminuir los casos coercitivos de este tipo de violencia dentro de este tema y aminorar los riesgos que enfrentan niños, niñas y adolescentes. ${ }^{9}$

República de Chile, Ministerio de Justicia y Derechos Humanos, Servicio Nacional de Menores, "Orientaciones técnicas para concurso de proyectos. Programa de protección especializada en reinserción educativa", http:// www.siteal.iiep.unesco.org/sites/default/files/sit_accion_files/6451.pdf (acceso diciembre 27, 2020), 3.

9 Organización de las Naciones Unidas para la Educación, la Ciencia y la Cultura [Unesco], Orientaciones técnicas internacionales sobre educación en sexualidad (Santiago: Unesco, 2010), 73. 
La Unesco considera que una inadecuada salud sexual es la razón principal del elevado número de infecciones de transmisión sexual en jóvenes. Resolver este problema es un factor crucial desde una perspectiva social y económica, dado que las ITS, los abortos inseguros y los embarazos no planeados son una onerosa carga para el presupuesto de las familias e impactan los recursos gubernamentales. ${ }^{10} \mathrm{~A}$ su vez, una adecuada educación en sexualidad propicia relaciones contextualizadas con la diversidad del mundo. ${ }^{11}$

Los profesionales de la educación también defienden este enfoque en la infancia y la adolescencia porque hace que el público-objetivo sea más consciente de sus propios derechos:

La educación sexual es la posibilidad de preservar a los niños y adolescentes de posibles abusos. La educación sexual en la escuela puede funcionar por la no sumisión de niños y adolescentes a las relaciones de poder y violencia que nuestra sociedad patriarcal, machista y sexista nos ha impuesto. Por eso tanta resistencia de sectores de parte de la sociedad, para que las transformaciones de las relaciones de poder no sucedan. ${ }^{12}$

Un estudio realizado en América Latina encontró que los niños acosados en entornos escolares tienen menor rendimiento en lectura y matemáticas, ${ }^{13}$ lo que limita, a futuro, las oportunidades laborales. Los expertos dicen que la educación en sexualidad es esencial para prevenir la violencia contra las mujeres, así como contra la comunidad LGBTIQ+ ${ }^{14}$ y el acoso escolar. Indica Frischeisen: "Es imposible alcanzar niveles razonables de violencia sin que, en las escuelas, desde la educación de la primera infancia, haya una preparación". ${ }^{15}$

Así mismo, estudiar la misoginia dentro de la educación sexual tiene un papel importante para lograr la igualdad de género. "La historia de la desigualdad de género facilita entender y generar conciencia sobre la violencia sistemática contra

10 Unesco, Orientaciones, 3.

11 Unesco, Orientaciones, 33.

12 Lara Tôrres, "Educação sexual nas escolas e a prevenção em caso de abuso", Leia Já, Sec. Educação, 31 de agosto de 2019, https://www.leiaja.com/carreiras/2020/08/31/educacao-sexual-nas-escolas-e-prevencao-em-caso-de-abuso

13 República de Colombia, Departamento Nacional de Planeación, Bases del Plan nacional de desarrollo 2018-2022 (Bogotá: Autor, 2018), 393.

14 Lesbiana, gay, bisexual, transgénero, transexual, travesti, intersexual, queer y más.

15 Luiza Cristina Frischeisen, "Educação de gênero na escola previne feminicídios", https://agenciabrasil.ebc. com.br/politica/noticia/2018-09/educacao-de-genero-na-escola-previne-feminicidios-dizem-especialistas (acceso octubre 27, 2020). 
las niñas y las mujeres hoy en día. Implica revisar el pasado para entender los relacionamientos actuales". ${ }^{16}$

Las niñas que reciben educación sexual integral tienen menos probabilidades de quedar embarazadas en la adolescencia, y más probabilidades de contar con herramientas educativas que permiten dotarles de los conocimientos, la confianza y de información veraz y científica sobre la salud sexual y reproductiva. ${ }^{17}$

Un estudio colombiano mostró que el 48 \% de las víctimas de abuso sexual tenían ideación suicida. ${ }^{18}$ Otro aspecto son los episodios de homofobia, que causan intentos de suicidio, discriminación, depresión, ansiedad, consumo de sustancias psicoactivas y baja autoestima, entre otros. ${ }^{19}$ Puesto que la educación sexual previene eventos de agresión y abuso, ${ }^{20}$ también puede contribuir a la reducción de intentos suicidas.

En el ámbito económico, solo en 2018, los países latinoamericanos perdieron un promedio de $0,35 \%$ del producto interno bruto (PIB) debido al embarazo adolescente. ${ }^{21} \mathrm{Si}$ Colombia hubiera implementado programas eficaces para prevenirlo habría ahorrado aproximadamente 5000 millones de dólares en el año, equivalentes al 0,56 \% del PIB. ${ }^{22}$ Para Tobar, la importancia de este debate está directamente relacionada con el progreso de la región: "[...] el embarazo adolescente es una fábrica de pobres en América Latina". ${ }^{23}$

16 Red por los derechos de la Infancia en México [Redim], La desigualdad de género comienza en la infancia. Manual teórico-metodológico para transversalizar la perspectiva de género en la programación con enfoque sobre derechos de la infancia (Ciudad de México: Autor, 2016), 36.

17 Redim, La desigualdad, 72.

18 Mónica Patricia Pérez Prada et al., "Intento e ideación suicida y su asociación con el abuso sexual en adolescentes escolarizados de Boyacá-Colombia". Diversitas 13, núm: 1 (2017): 96, https://www.redalyc. org/pdf/679/67952833007.pdf (acceso noviembre 17, 2020).

19 Carlos Alejandro Pineda Roa, "Factores asociados con riesgo de suicidio de adolescentes y jóvenes autoidentificados como lesbianas, gays y bisexuales: estado actual de la literatura", Revista Colombiana de Psiquiatría 48, núm. 1 (2017): 142, https://www.researchgate.net/publication/262878444_Factores_asociados_con_riesgo_de_suicidio_de_adolescentes_y_jovenes_autoidentificados_como_lesbianas_gays_y_bisexuales_estado_actual_de_la_literatura (acceso noviembre 17, 2020).

20 Tôrres, "Educação".

21 Unfpa, "El impacto socioeconómico del embarazo en la adolescencia representa 1242 millones de dólares o $0,35 \%$ del PIB anual para seis países de América Latina".

22 DW, "ONU: El embarazo adolescente es una fábrica de pobres en América Latina", DW, Sec. América Latina, 4 de noviembre de 2004, http://www.dw.com/es/ onu-el-embarazo-adolescente-es-una-f\%C3\%Albrica-de-pobres-en-am\%C3\%A9rica-latina/a-55569024

$23 \mathrm{DW}$, "ONU". 
Para inducir y promover esta atención a niños y adolescentes, la ONU ha elaborado instrucciones sobre cómo abordar la educación sexual. En primer lugar, el enfoque debe incluir las cuestiones de diversidad y género como una forma de promover el respeto. Los padres deben ser incluidos para que el proceso de aprendizaje y conocimiento continúe en casa. Además, la educación sexual también puede combinarse con otras disciplinas de manera transversal. ${ }^{24}$

\section{Educación sexual en convenciones internacionales}

El tema de la educación sexual está presente, directa o indirectamente, en diversas convenciones internacionales, comenzando con la Declaración universal de derechos humanos, de 1948, cuyo Artículo 26 está dedicado a la educación y resalta su principal esencia:

La educación tendrá por objeto el pleno desarrollo de la personalidad humana y el fortalecimiento del respeto a los derechos humanos y a las libertades fundamentales; favorecerá la comprensión, la tolerancia y la amistad entre todas las naciones y todos los grupos étnicos o religiosos, y promoverá el desarrollo de las actividades de las Naciones Unidas para el mantenimiento de la paz. ${ }^{25}$

Es posible inferir, a partir de este pasaje, algunas de las condicionales para la educación sexual, pues, entre varias funciones, el estudio de la sexualidad en el entorno escolar tiene como objetivo el desarrollo de la personalidad del ser humano. Chile, Colombia y Ecuador se encuentran entre los países miembros fundadores de la Organización de Naciones Unidas y los signatarios de la Declaración. ${ }^{26}$ Sin embargo, es importante recordar que el documento "no tiene valor obligatorio; es decir, al ser aprobada por medio de una Resolución de la Asamblea General, no posee valor vinculante para los Estados, aunque sí tiene un valor moral innegable". ${ }^{27}$

Si bien la Declaración Universal de Derechos Humanos era sólo una Declaración, sin medios para hacerla ejecutable, la Comisión de Derechos Humanos comenzó, aun en 1949, la preparación de los Pactos, a prepararse en forma de

24 Organización de las Naciones Unidas para la Educación, la Ciencia y la Cultura [Unesco], International Technical Guidance on Sexuality Education: An Evidence-Informed Approach (París: Unesco, 2018), 13.

25 Asamblea General de las Naciones Unidas, Declaración universal de los derechos humanos (París, 10 de diciembre 1948), art. 26.

26 Organización de las Naciones Unidas [ONU], "Estados miembros", http://www.un.org/es/member-states/ index.html (acceso noviembre 13, 2020).

27 Corpe S. L. et al., Guardia civil. Escala de cabos y guardias. Temario (Sevilla: Rodio, 2020), 58. 
convenios internacionales. En 1954, presentó dos anteproyectos de pactos que se ocupaban por separado de los derechos, un pacto que contenía derechos civiles y políticos y otro con derechos económicos, sociales y culturales. ${ }^{28}$

El Pacto internacional de derechos económicos, sociales y culturales aparece en 1966. Su Artículo 13 explora el tema de la educación y aborda temas inherentes a los logros obtenidos por medio de la educación sexual:

Los Estados Parte en este Pacto reconocen el derecho de todos a la educación. Coinciden en que la educación debe orientarse al pleno desarrollo de la personalidad humana y al sentido de su dignidad, así como a fortalecer el respeto de los derechos humanos y las libertades fundamentales. También están de acuerdo en que la educación debe permitir que todas las personas participen eficazmente en una sociedad libre, promuevan la comprensión, la tolerancia y la amistad entre todas las naciones y todos los grupos raciales, étnicos o religiosos, y promuevan las actividades de mantenimiento de la paz de las Naciones Unidas. ${ }^{29}$

En 1988 surgió el Protocolo de San Salvador, adicional a la Convención americana sobre derechos humanos. En su Artículo 10, los países se comprometen a proporcionar educación sobre la prevención de los problemas de salud. Chile, Colombia y Ecuador forman parte de los firmantes del protocolo. ${ }^{30}$ Una vez más, si no especifica el tema de la educación para la sexualidad, menciona objetivos y metas que, como se identifica en este estudio, se logran con este enfoque.

La Convención sobre los derechos del niño aborda los derechos inherentes a la infancia, incluidas las obligaciones comunes a los Estados con respecto a la educación. Entre sus artículos, el que más está relacionado con el presente estudio es el número 19:

Los Estados Parte adoptarán todas las medidas legislativas, administrativas, sociales y educativas apropiadas para proteger al niño de toda forma de violencia

28 Rogério Gesta Leal y Clovis Gorczevski, "Artigo 13" en Comentários ao Pacto internacional dos direitos econômicos, eds. Wagner Balera y Vladimir Oliveira da Silveira (San Pablo: Classica, 2013), 218-219.

29 Asamblea General de las Naciones Unidas, International Covenant on Economic, Social and Cultural Rights (París, 16 de diciembre de 1966), art. 16.

30 Organización de los Estados Americanos [OEA], Comisión Interamericana de Derechos Humanos, Protocolo adicional a la Convención americana sobre derechos humanos en materia de derechos económicos, sociales y culturales, "Protocolo de San Salvador" (El Salvador, 17 de noviembre de 1988), art. 10. 
física o mental, delitos o abuso, negligencia o trato irrazonable, malos tratos o explotación, incluido el abuso sexual, mientras el niño esté bajo la custodia de los padres, tutor legal o cualquier otra persona responsable de ello. ${ }^{31}$

Dentro de esta Convención, también se destacan los Artículos 28 y 29, los cuales plantean la educación como una forma de ejercer de manera progresiva e igualitaria las oportunidades de derecho.

La Conferencia internacional de las naciones unidas sobre la población y el desarrollo tuvo como resultado un plan de acción con compromisos para mejorar la vida de la población, incluidos temas sobre planificación familiar y salud sexual. La educación sexual fue vista como una de las formas de alcanzar los objetivos mencionados en la Conferencia. ${ }^{32}$ A partir de esta, las convenciones trataron con más claridad la importancia de una educación para la sexualidad.

Del mismo modo, la Conferencia internacional de la mujer, de Beijing, propuso garantías que incluyeron la educación en salud sexual. ${ }^{33}$ El evento funcionó como un "hito esencial en el proceso de consolidación de los derechos de las mujeres a nivel internacional". ${ }^{34}$

La Convención interamericana para prevenir, sancionar y erradicar la violencia contra la mujer establece que los Estados parte deben adoptar, de manera progresiva, programas para promover el derecho de la mujer a una vida libre de violencia. ${ }^{35}$ Para eso también sugiere la educación:

Modificar los patrones socioculturales de conducta de hombres y mujeres, incluyendo el diseño de programas de educación formales y no formales apropiados a todo nivel del proceso educativo, para contrarrestar prejuicios y costumbres y todo otro tipo de prácticas que se basen en la premisa de la

31 Asamblea General de las Naciones Unidas, Convención de los derechos del niño (París, 20 de noviembre de 1989), art. 19.

32 Organización de las Naciones Unidas [ONU], Informe de la Conferencia internacional sobre la población y el desarrollo. El Cairo, 5 a 13 de septiembre de 1994 (Nueva York: Autor, 1995), 30.

33 Organización de las Naciones Unidas [ONU], Informe de la Cuarta conferencia mundial sobre la mujer. Beijing, 4 a 15 de septiembre de 1995 (Nueva York: Autor, 1996), 4.

34 Tathiana Haddad Guarnieri, "Os direitos das mulheres no contexto internacional da criação da ONU à Conferência de Beijing", Revista Eletrônica da Faculdade Metodista Granbery, núm. 8 (2010): 26, http:// re.granbery.edu.br/artigos/MzUx.pdf (acceso enero 24, 2021).

35 Organización de los Estados Americanos [OEA], Convención interamericana para prevenir, sancionar y erradicar la violencia contra la mujer (Convención de Belém do Pará) (Belén, 9 de junio de 1994), art. 8, lit. b. 
inferioridad o superioridad de cualquiera de los géneros o en los papeles estereotipados para el hombre y la mujer que legitiman o exacerban la violencia contra la mujer. ${ }^{36}$

Por otra parte, el informe del Consejo de Derechos Humanos de las Naciones Unidas, de 2018, enfatiza la necesidad de que los países promuevan la igualdad de género y los derechos de las niñas y las mujeres para una concienciación a largo plazo, al igual que programas de formación de docentes que aborden la prevención de "violencia sexual y de género, garantizando el acceso universal a una educación sexual integral y con base empírica" ${ }^{37}$ El documento sugiere a los países que elaboren programas educativos, en particular enfocados hacia una educación sexual "en consonancia con el desarrollo evolutivo del niño, en donde se explique en qué consiste el consentimiento, el respeto de los límites y lo que constituye un comportamiento inaceptable, como el acoso sexual y la violencia de género". ${ }^{38}$

\section{La educación sexual como un derecho humano}

Como se mencionó, la educación sexual entendida como derecho humano apareció en las convenciones internacionales a partir de la década de 1990. Un retraso considerable, si pensamos que los tratados nacieron después de la Segunda Guerra Mundial.

El marco de los derechos humanos, con sus órganos internacionales, tribunales y convenciones, puede ser desesperadamente lento en su respuesta o incapacidad constante para alcanzar sus objetivos finales; pero la verdad es que no hay otra mejor estructura disponible para hacer frente a estos problemas. ${ }^{39}$

Hay resistencia frente a este tema y en muchos países está prohibido o afronta intentos de prohibición. En 2020, una resolución emitida en México planteó al Consejo de Derechos Humanos de la ONU la importancia del acceso a la educación sexual y a los derechos de salud sexual, en especial de las mujeres. Sin embargo,

36 OEA, Convención interamericana para prevenir, sancionar y erradicar la violencia contra la mujer (Convención de Belém do Pará), art. art. 8, lit. b.

37 Organización de las Naciones Unidas [ONU], Informe del Consejo de Derechos Humanos (Nueva York: Autor, 2019), 157.

38 ONU, Informe, 201

39 Lynn Hunt, Inventing Human Rights: A History (Nueva York: W. W. Norton, 2007), 213. 
algunos países han estado en contra, como Egipto, Arabia Saudita, Rusia, Brasil, Qatar, Bahréin, Pakistán e Irak. ${ }^{40}$

La dificultad para abordar la educación sexual radica en una perspectiva desde la mirada cultural.

Cuando una niña cuenta que está siendo abusada, se siente culpable, se siente sucia $[. .$.$] dice que no cuenta porque su mamá la va a golpear [...] pero,$ ¿cómo es posible que una niña tan pequeña sienta eso? [...]. La respuesta es porque así la han educado. ${ }^{41}$

La solución radica en distintos ámbitos de la administración pública, en particular y directamente en el de la educación. Además, también hay un desafío si la propuesta se basa en el corte transversal. "Deconstruir las prácticas pedagógicas realizadas hace años e insertar una nueva práctica no es una cosa sencilla. Pero necesitamos buscar soluciones a las demandas de los problemas contemporáneos y a la vida cotidiana de los estudiantes". ${ }^{42}$ Figueiró expone con claridad los retos para la educación en este campo:

¿Cuál sería la función del maestro que está dispuesto a hablar sobre la sexualidad en el espacio escolar? Algunos padres están preocupados, precisamente, porque temen que los maestros transmitan a sus hijos los valores que ellos, los maestros, defienden. Así, por ejemplo, los padres conservadores, que abogan por la virginidad hasta el matrimonio (para las hijas, la mayor parte del tiempo), temen que los maestros puedan predicar valores divergentes, fomentando, en este caso, el sexo antes del matrimonio. Lo contrario también puede suceder, es decir, los padres que quieren que sus hijos sean libres para decidir responsablemente sobre su vida sexual, temen que los maestros conservadores infundan ideas de pecado. ¿Tendrían el derecho, maestros, de influir en sus alumnos con sus valores personales sobre lo que consideran correcto o incorrecto? Ciertamente no; depende de ellos crear varias oportunidades de reflexión, para que los

40 Jamil Chade, "Brasil lavará as mãos em ação de ultraconservadores na ONU", UOL, Sec. Noticias, 16 de julio de 2020, https://noticias.uol.com.br/colunas/jamil-chade/2020/07/16/em-manobra-brasil-lava-as-maos-em-acao-de-ultraconservadores-na-onu.htm

${ }^{41}$ Luis Miguel Bermúdez y Simón Granja Matías, Sexualidad sin pelos en la lengua (Bogotá: Intermedio, 2019), 22.

42 Luciana Uchôa Barbosa et al., "A educação sexual nos documentos das políticas de educação e suas ressignificações", Acervo Saúde 11, núm. 10 (2019): 9, https://doi.org/10.25248/reas.e772.2019 (acceso julio 12, 2020). 
estudiantes puedan pensar y discutir con sus compañeros, para que puedan formar su propia opinión. ${ }^{43}$

Esta dificultad se puede traducir en números. Respecto a las tasas de nacimiento en Chile, "las más altas se registran en los grupos etarios más jóvenes y, si bien el número de madres adolescentes disminuye entre 2013-2015, las madres de 11 años han aumentado"; 44 el promedio de adolescentes madres o embarazadas es del $6 \%$, y en adolescentes de 12 a 19 años crece al 9,2\%, ${ }^{45}$ mientras que Chile tiene las tasas más bajas de embarazo adolescente en América Latina.

En Colombia, las cifras llaman la atención:

[...] en Colombia el 23,4 \% de las mujeres entre 20 y 24 años se unió conyugalmente antes de los 18 años, y el 4,9\% se unió antes de los 15 años. Así mismo, el 13,3 \% de las adolescentes entre 15 y 19 años ya están casadas o en unión libre, y en zonas rurales esta cifra asciende al 21,5\%. Para los años 2016 y 2017 se registraron 470 matrimonios con o entre personas menores de edad en notarías de Colombia. A su vez, las mujeres se unen a más temprana edad que los hombres, el $25 \%$ de las mujeres entre los 30 y los 34 años reportaron haberse unido por primera vez antes de los 18 años, frente al 9,9\% de los hombres [...]. En el 44,6\% de mujeres entre los 13 y los 19 años que ya son madres, la edad del padre de su primer hijo la supera por lo menos en 6 años; un 19,5\% en por lo menos 10 años; y en el 4,6\% de los casos, el padre es 20 años mayor. ${ }^{46}$

Una investigación en Ecuador ha hallado que 21,4 \% de niñas, niños y adolescentes han sido víctimas de abuso sexual. "Seis de cada diez estudiantes han sido víctimas de violencia escolar y $26 \%$ de quienes sufren acoso escolar afirman que han intentado suicidarse". ${ }^{47}$

43 Mary Neide Damico Figueiró, "Educação sexual: como ensinar no espaço da escola", Linhas 7, núm. 1 (2006): 2, https://www.periodicos.udesc.br/index.php/linhas/article/view/1323 (acceso julio 12, 2020).

44 República de Chile, Ministerio de la Mujer y la Equidad de Género, "Cuarto plan nacional de igualdad entre mujeres y hombres 2018 - 2030", https://www.siteal.iiep.unesco.org/sites/default/files/sit_accion_files/ ch_8001.pdf (acceso diciembre 11, 2020), 49.

45 República de Chile, Ministerio de la Mujer y la Equidad de Género, "Cuarto plan nacional de igualdad entre mujeres y hombres 2018-2030", 49.

46 República de Colombia, Departamento Nacional de Planeación, Bases, 1040-1041.

47 República del Ecuador, Gobierno Nacional, "Pacto del gobierno nacional con niños, niñas y adolescentes contra la violencia", https://www.siteal.iiep.unesco.org/sites/default/files/sit_accion_files/ec_6130.pdf (acceso septiembre 18, 2020), 3. 


\section{Chile}

Desde 2010, Chile tiene la Ley 20 418, que instituyó normas de información y prestaciones sobre regulación de la fertilidad. En el Artículo 1 se definió que los establecimientos educativos debían incluir en la enseñanza media un programa de educación sexual. El objetivo fue ofrecer contenidos que propendieran por una sexualidad responsable y que informara sobre los diversos métodos anticonceptivos existentes. La aplicación de la ley ganó fuerza, pues un estudio mostró que las tasas de embarazo entre las adolescentes que participaron en programas de educación sexual disminuyeron significativamente. ${ }^{48}$

En 2018, la educación sexual en ese país avanzó como una oportunidad de "propuesta formativa, preventiva y de resguardo de derechos de niños, niñas y adolescentes durante la trayectoria en el sistema escolar". ${ }^{49}$ Los Ministerios de Educación, Salud y de la Mujer y la Equidad de Género emitieron una disposición que los reconoció como sujetos de los derechos amparados en las convenciones y los tratados internacionales ratificados por el país ${ }^{50}$ y destacaron que la política nacional se trataba de una "educación en sexualidad laica y humanista como un derecho social". ${ }^{51}$ Uno de los objetivos era garantizar la entrega de la información necesaria a los alumnos para que se formaran su propia opinión.

Chile reconoce que:

Un alto número de adolescentes inicia su vida sexual a más temprana edad, sin protección anticonceptiva y, por ende, con un alto riesgo de embarazo y de infecciones de transmisión sexual. La población adolescente más pobre se encuentra dentro de los grupos más vulnerables debido a las escasas posibilidades y oportunidades para un desarrollo autónomo de su vida: se exponen a relaciones sexuales sin consentimiento, pueden ser víctimas de abuso sexual, no acceden a información adecuada en torno a la prevención o

48 Biblioteca del Congreso Nacional de Chile, "Historia de la Ley 20 418. Fija normas sobre información, orientación y prestaciones en materia de regulación de la fertilidad", http://www.codajic.org/sites/www. codajic.org/files/Historia\%20de\%20la\%20Ley\%2020418.pdf (acceso diciembre 27, 2020), 20-21.

49 República de Chile, Ministerio de Educación, Ministerio de Salud y Ministerio de la Mujer y la Equidad de Género, "Educación sexual: estrategia en sexualidad, afectividad y género", http://www.siteal.iiep.unesco. org/sites/default/files/sit_accion_files/6457.pdf (acceso diciembre 2, 2020), 3.

50 República de Chile, Ministerio de Educación, Ministerio de Salud y Ministerio de la Mujer y la Equidad de Género, "Educación sexual: estrategia en sexualidad, afectividad y género", 7.

51 República de Chile, Ministerio de Educación, Ministerio de Salud y Ministerio de la Mujer y la Equidad de Género, "Educación sexual: estrategia en sexualidad, afectividad y género", 25. 
inician relaciones sexuales sin protección y se enfrentan a barreras para acceder a servicios de salud sexual y reproductiva. ${ }^{52}$

Al reconocer los desafíos, el país desarrolla las actividades propuestas por el Ministerio de Educación sobre la temática de educación sexual ${ }^{53}$ como:

- Orientaciones para la implementación de un programa en sexualidad y género en establecimientos educacionales.

- Guía didáctica para educación sexual, con material para docentes.

- Manual para facilitadores de prevención del acoso escolar homofóbico y transexual en escuelas.

- Orientaciones para estudiantes LGBTIQ+.

- Protocolo de actuación para establecimientos educativos del país frente a estudiantes transexuales.

- Orientaciones para promover escuelas inclusivas (género, orientación sexual, identidad de género, estudiantes con VIH/SIDA e ITS, estudiantes embarazadas, madres y padres adolescentes).

- Revisión y ajuste de retención en el sistema escolar de estudiantes embarazadas, madres y padres adolescentes, con protección de madres adolescentes con necesidades educativas especiales.

- Implementación de un sistema de apoyo y un programa de educación en sexualidad, afectividad y género en establecimientos educativos.

El Cuarto plan nacional de igualdad entre hombres y mujeres 2018-2030 desarrolla metas asociadas a los derechos y grupos de poblacionales específicos. Los indicadores muestran que:

52 República de Chile, Ministerio de la Mujer y la Equidad de Género, "Cuarto plan nacional de igualdad entre mujeres y hombres 2018-2030", 49.

53 República de Chile, Ministerio de Educación, Ministerio de Salud y Ministerio de la Mujer y la Equidad de Género, "Educación sexual: estrategia en sexualidad, afectividad y género", 24. 
Chile ha realizado grandes avances en materia de cobertura de salud y de derechos sexuales y reproductivos de las mujeres, y muchos de sus indicadores son similares a los de los países desarrollados (por ejemplo, una baja mortalidad materna), pero aún muestra deficiencias en la atención y prevención de salud a colectivos específicos de mujeres: trans, lesbianas, rurales, migrantes y a ciertos grupos etarios, especialmente adolescentes y personas adultas mayores. ${ }^{54}$

A pesar de que Chile tiene la menor tasa de adolescentes embarazadas en América Latina, el país entiende que los números existentes obedecen a la falta de programas continuados de educación en sexualidad con amplia cobertura: "La educación sexual y reproductiva orientada a la paternidad y maternidad responsables a partir de la educación escolar y el acceso a regulación de fertilidad para la población vulnerable, son elementos esenciales de salud pública que pueden ser mejorados". ${ }^{55}$

La meta es que, hasta el año 2030, todos los establecimientos del sistema educativo brinden educación sexual integral. ${ }^{56}$

Surgieron otros documentos diseñados para instituir medidas de equidad en tema de derechos, como la Educación para la igualdad de género, con temas de formación para docentes, con enfoque de género para adolescentes por medio de cursos sobre discriminación y sexualidad. ${ }^{57}$

Dentro de la Política nacional de niñez y adolescencia, el Sistema integral de garantías de derechos para el período de 2015-2025 tiene como estrategia "propiciar acciones tendientes al desarrollo de una sexualidad informada y segura de acuerdo al curso de vida" ${ }^{8}$ y "reforzar la formación en sexualidad y afectividad, sin discriminación por género, identidad sexual o ante la presencia de situaciones de discapacidad" ${ }^{59}$

54 República de Chile, Ministerio de la Mujer y la Equidad de Género, "Cuarto plan nacional de igualdad entre mujeres y hombres 2018-2030", 49.

55 Biblioteca del Congreso Nacional de Chile, "Historia de la Ley 20 418. Fija normas sobre información, orientación y prestaciones en materia de regulación de la fertilidad", 48.

56 República de Chile, Ministerio de la Mujer y la Equidad de Género, "Cuarto plan nacional de igualdad entre mujeres y hombres 2018-2030", 53.

57 República de Chile, Ministerio de Educación, Unidad de Equidad de Género, "Educación para la igualdad de género. Plan 2015-2018", https://www.siteal.iiep.unesco.org/sites/default/files/sit_accion_files/siteal_chile_0652. pdf (acceso agosto 10, 2020), 28.

58 República de Chile, Consejo Nacional de la Infancia, "Política nacional de niñez y adolescencia. Sistema integral de garantías de derechos de la niñez y adolescencia 2015-2025", https://www.siteal.iiep.unesco. org/sites/default/files/sit_accion_files/siteal_chile_0654.pdf (acceso diciembre 11, 2020), 86.

59 República de Chile, Consejo Nacional de la Infancia, "Política nacional de niñez y adolescencia. Sistema integral de garantías de derechos de la niñez y adolescencia 2015-2025", 89. 
Las bases curriculares de la educación infantil tienen conceptos inclusivos acordes con la Unesco sobre temas que señalan la diversidad sexual y de género como forma de brindar oportunidades de aprendizaje igualitarias. ${ }^{60}$ Adicionalmente, en los lineamientos técnicos para la mejora de la calidad de la educación, hay puntos relevantes:

[...] para promover el desarrollo integral e inclusivo de la niña y el niño, se requiere un respeto y valoración de su género. Por tanto, el/la mediador debe eliminar las barreras sociales de estereotipos, que muchas veces provienen de la cultura y no del propio sentido que él o ella le da a su ser. El género debe vivirse como una construcción personal que le permita al párvulo sentirse cómodo, valorado y respetado independiente de la situación cultural en la que vive. Concebir que la cultura se transforma, es concebir que el género también se trasforma. Y hoy en día, una demanda social, que cada vez se hace más latente, es la libertad en la elección del modo de vivir la sexualidad. ${ }^{61}$

Este énfasis en la educación sexual se construyó con análisis y diagnósticos intersectoriales que permitieron visibilizar que faltaba educación en sexualidad para estudiantes, profesores, padres y apoderados. ${ }^{62}$ Así, fue posible ampliar los conceptos para la educación en Chile, como "comprender y apreciar la importancia que tienen las dimensiones afectiva, espiritual, ética y social, para un sano desarrollo sexual". ${ }^{63}$

De la misma forma, programas de protección especializada en reinserción educativa también tienen como obligación abarcar planes de "educación sexual, incluyendo temáticas como prevención del embarazo adolescente, vinculación de afectividad y sexualidad, y conocimiento y aceptación de la diversidad sexual". ${ }^{64}$

60 República de Chile, Ministerio de Educación, "Bases curriculares de la educación parvularia", https://www. siteal.iiep.unesco.org/sites/default/files/sit_accion_files/6461.pdf (acceso agosto 8, 2020).

61 República de Chile, Junta Nacional de Jardines Infantiles, "Lineamientos técnicos. Marco pedagógico para la mejora de la calidad de las prácticas educativas", http://www.siteal.iiep.unesco.org/sites/default/files/ sit_accion_files/6466.pdf (acceso diciembre 11, 2020), 21.

62 República de Chile, Ministerio de Educación. "Modelo de gestión intersectorial. Aulas del bien estar", https:// www.siteal.iiep.unesco.org/sites/default/files/sit_accion_files/6424.pdf (acceso agosto 18, 2020), 9.

63 República de Chile, Ministerio de Educación, "Objetivos fundamentales y contenidos mínimos obligatorios de la educación básica y media”, https://www.siteal.iiep.unesco.org/sites/default/files/sit_accion_files/ siteal_chile_0636.pdf (acceso agosto 14, 2020), 25.

64 República de Chile, Ministerio de Justicia y Derechos Humanos, Servicio Nacional de Menores, "Orientaciones técnicas para concurso de proyectos. Programa de protección especializada en reinserción educativa”, 27. 


\section{Colombia}

En las bases del Plan nacional de desarrollo 2018-2022 se habla de estrategias para la consolidación del Sistema nacional de convivencia escolar y formación para el ejercicio de los derechos humanos, sexuales y reproductivos, y la prevención y mitigación de la violencia escolar, previstas en la Ley 1620 de 2013. Esta Ley fue creada para identificar y hacer seguimiento a los "casos de acoso, violencia escolar y de vulneración de derechos sexuales y reproductivos que afecten a los niños, niñas y adolescentes de los establecimientos educativos". ${ }^{65}$ El sistema tiene por objetivo fomentar acciones para la educación sexual, garantizar protección de niñas, niños y adolescentes en los espacios educativos y atender los casos de violencia y acoso escolar o vulneración de derechos sexuales y reproductivos para reducir el embarazo de adolescentes y las enfermedades de transmisión sexual. ${ }^{66}$ El documento menciona garantías para la protección frente al acoso, a la violencia escolar y al ciberacoso y habla sobre involucrar a la comunidad educativa en una reflexión acerca de la vulneración de los derechos sexuales.

Entre los objetivos del Plan está promover la inclusión productiva de los jóvenes con el "fomento del autocuidado, la sexualidad responsable y los derechos sexuales de los adolescentes y jóvenes para la toma de decisiones". ${ }^{67}$ Así mismo, el Plan decenal de salud pública plantea el fortalecimiento de la política de educación sexual, de modo que involucre la comunidad de "niñas, niños, adolescentes, jóvenes, padres, madres, cuidadores, profesorado y demás personas que se relacionan con las instituciones educativas" ${ }^{68}$ El Plan de desarrollo aborda la importancia de la expansión de la cobertura del Programa de educación para la sexualidad y construcción de la ciudadanía, y que contribuyó para generar un precursor en el país:

La Sentencia T-478 de 2015 de la Corte Constitucional, más conocida como la Sentencia Sergio Urrego, ${ }^{69}$ marca un precedente en términos de la garantía del derecho a la educación libre de discriminación, a la igualdad, a la intimidad, al

65 República de Colombia, Congreso de la República, Ley 1620 de 2013, "Por la cual se crea el Sistema nacional de convivencia escolar y formación para el ejercicio de los derechos humanos, la educación para la sexualidad y la prevención y mitigación de la violencia escolar" (Bogotá: Diario Oficial núm. 48 733, 15 de marzo de 2013), art. 28.

66 República de Colombia, Congreso de la República, Ley 1620 de 2013, art. 28.

67 República de Colombia, Departamento Nacional de Planeación, Bases, 371.

68 República de Colombia, Departamento Nacional de Planeación, Bases, 392.

69 En 2014, Sergio Urrego, de 16 años, decidió quitarse la vida, después de haber sufrido discriminación por parte de las directivas del colegio donde estudiaba, en Bogotá (Colombia), debido a su orientación sexual. El tema abrió un debate en el país y cambió demandas constitucionales. 
libre desarrollo de la personalidad y al respeto por la expresión de la identidad de género o la orientación sexual. ${ }^{70}$

Otro objetivo del Plan es "promover la educación sexual y el bienestar de las niñas, niños y adolescentes y prevenir el embarazo adolescente, las uniones tempranas y el matrimonio infantil". ${ }^{71}$

El Código de la Infancia y la Adolescencia establece la obligatoriedad de una cátedra de educación para la sexualidad en la enseñanza media y superior. El propósito es dar énfasis al respeto por la dignidad de los derechos de los menores de edad, pero el documento está enfocado en avanzar en temas sobre prevención y lucha contra el abuso sexual. ${ }^{72}$

La Ley general de educación instituye la enseñanza obligatoria de educación sexual, impartida "de acuerdo con las necesidades psíquicas, físicas y afectivas de los educandos según su edad". ${ }^{73}$

Entre los objetivos de la Política nacional de sexualidad, derechos sexuales y derechos reproductivos está fortalecer la educación sexual para los prestadores de servicios públicos orientados a reconocer la sexualidad como una condición humana, con un enfoque laico. ${ }^{74}$ La política busca ampliar el acceso al Programa de educación para la sexualidad y construcción de ciudadanía por medio de docentes preparados para "superar posturas moralistas" las instituciones educativas públicas con educación sexual basada en el ejercicio de derechos humanos, sexuales y reproductivos, desde un enfoque de género y diferencial" ${ }^{76}$

República de Colombia, Departamento Nacional de Planeación, Bases, 448.

República de Colombia, Departamento Nacional de Planeación, Bases, 441.

72 República de Colombia, Congreso de la República, Ley 1098 de 2006, "Por la cual se expide el Código de la infancia y la adolescencia" (Bogotá: Diario Oficial núm. 46 446, 8 de noviembre de 2006), art. 44.

73 República de Colombia, Congreso de la República, Ley 115 de 1994, "Por la cual se expide la Ley general de educación" (Bogotá: Diario Oficial núm. 41 214, 8 de febrero de 1994), art. 14.

74 República de Colombia, Ministerio de Salud, "Política nacional de sexualidad, derechos sexuales y derechos reproductivos", http://www.siteal.iiep.unesco.org/sites/default/files/sit_accion_files/3302.pdf (acceso diciembre $11,2020), 133$.

75 República de Colombia, Ministerio de Salud, "Política nacional de sexualidad, derechos sexuales y derechos reproductivos", 101.

76 República de Colombia, Ministerio de Salud, "Política nacional de sexualidad, derechos sexuales y derechos reproductivos", 113. 
Se fijaron los siguientes lineamientos para la prevención del embarazo adolescente:

A nivel general, con base en la Constitución de 1991 se ha inferido que los Derechos Sexuales y Reproductivos (DSR) forman parte de los derechos fundamentales y de los Sociales, Económicos y Culturales (DESC), como lo ha señalado la Jurisprudencia Constitucional [...]. En ese contexto, la Corte Constitucional emitió la sentencia T-440/92, estableciendo la necesidad de abordar la educación sexual en el país. Es así como el Ministerio de Educación Nacional le otorgó carácter obligatorio a la educación sexual en las instituciones educativas mediante la Resolución 3353 de 1993. ${ }^{77}$

La Ley general de educación sanciona la obligatoriedad de la educación sexual mediante proyectos pedagógicos. ${ }^{78}$ La educación en la sexualidad y la emocionalidad está prevista en Colombia también desde la primera infancia, por medio del Manual operativo para la atención a la primera infancia. ${ }^{79}$

\section{Ecuador}

El Código de la Niñez y Adolescencia de Ecuador tiene como principios fundamentales la igualdad y la no discriminación, y sanciona que el Estado adopte las medidas para eso. El documento da garantías de acceso a la salud física, mental, psicológica y sexual e incluso a la información y educación sobre prevención en materia de salud y desarrollo. Entre los objetivos se encuentran desarrollar la personalidad; promover la paz; actuar a favor de los derechos humanos; garantizar la no discriminación, las libertades fundamentales y la tolerancia de las diversidades, y preparar niños, niñas y adolescentes para una ciudadanía responsable..$^{80}$

77 República de Colombia, Consejo Nacional de Política Económica y Social, "Documento Conpes Social núm. 147/2012. Lineamientos para el desarrollo de una estrategia para la prevención del embarazo en la adolescencia y la promoción de proyectos de vida para los niños, niñas, adolescentes y jóvenes en edades entre 6 y 19 años", http://www.siteal.iiep.unesco.org/sites/default/files/sit_accion_files/co_0413.pdf (acceso diciembre 22, 2020), 12.

78 República de Colombia, Consejo Nacional de Política Económica y Social, "Documento Conpes Social núm. 147/2012", 65.

79 Instituto Colombiano de Bienestar Familiar, "Manual operativo. Modalidad institucional para la atención a la primera infancia", https://www.siteal.iiep.unesco.org/sites/default/files/sit_accion_files/co_3307_manual_operativo_modalidad_institucional.pdf (acceso noviembre 11, 2020), 50.

80 República de Colombia, Congreso de la República, Ley 1098 de 2006. 
El Plan decenal de educación de Ecuador 2006-2015 institucionalizó la educación sexual en el sistema educativo. En 2006, 13000 maestros fueron capacitados y se incorporó la asignatura Educación de la Sexualidad en la formación profesional. ${ }^{81}$

En el Programa de Gobierno 2017-2021 se propone una "revolución de la juventud", que convierte al joven en "protagonista de una nueva sociedad". Y más:

Promoveremos la educación sexual y reproductiva de los jóvenes, junto a las mujeres y hombres jóvenes, para garantizar su derecho a tomar decisiones libres, informadas, voluntarias y responsables sobre su sexualidad. Daremos prioridad a las adolescentes, para la prevención de embarazos. ${ }^{82}$

El Plan nacional de desarrollo 2017-2021 tiene metas en cuanto a salud materna, sobre todo a embarazo adolescente. La falta histórica de una atención al tema puede ser traducido en números:

[... para el año 2015 el costo económico y social por la omisión de servicios de salud sexual y reproductiva llegó a US\$ 472,9 millones, lo que evidencia una deuda social en una adecuada educación sexual, reproductiva y de planificación familiar. [...] el embarazo adolescente merece una atención especial: en 2015 el porcentaje de nacimientos en mujeres entre 12 y 17 años fue de 10,2\%, mientras que en 2006 fue de 8,1\%. Esta problemática genera situaciones adversas, como la deserción escolar y la pobreza. [...] 6487 adolescentes abandonaron los estudios por esta razón, lo que conlleva situaciones de vulneración de derechos que afectan su proyecto de vida. ${ }^{83}$

En 2004, un documento alertó sobre los problemas sociales de las altas tasas de embarazo adolescente. El estudio muestra que la desnutrición crónica infantil está relacionada, en diversos casos, con la incidencia del embarazo adolescente. Estos

81 República del Ecuador, Ministerio de Educación y Cultura, "Plan decenal de educación del Ecuador 20062015", http://www.siteal.iiep.unesco.org/sites/default/files/sit_accion_files/ec_9029.pdf (acceso noviembre 28, 2020), 20.

82 República del Ecuador, Movimiento Alianza País, "Programa de Gobierno 2017-2021", http://www.siteal. iiep.unesco.org/sites/default/files/sit_accion_files/siteal_ecuador_0243.pdf (acceso noviembre 28, 2020), 84.

83 República del Ecuador, Consejo Nacional de Planificación, Toda una vida. Plan nacional de desarrollo 2017-2021 (Quito: Senplades, 2017), 51. 
datos tuvieron como premisa diseñar políticas públicas de educación sexual en niños, niñas y adolescentes. ${ }^{84}$

Como forma de prevenir y erradicar la violencia hacia mujeres y niñas, entre las normativas de la Agenda nacional de las mujeres y la igualdad de género 2014-2017 está la incorporación de la educación sexual en el sistema educativo. Nuevamente se hace referencia a los altos índices de adolescentes embarazadas: en 2013, 5 \% de niñas de 12 a 19 años eran madres o estaban en lactancia. Entre las propuestas estaba crear campañas informativas sobre educación sexual en los medios de comunicación. ${ }^{85}$

Entre los elementos constitutivos de la nación, el Artículo 32 habla del derecho a la salud, incluso del acceso permanente a servicios de promoción y atención integral a la salud, salud sexual y educación. ${ }^{86}$ Además, la Constitución garantiza la búsqueda de "erradicar todas las formas de violencia en el sistema educativo y velar por la integridad física, psicológica y sexual de las estudiantes y los estudiantes" ${ }^{87}$

Con el propósito de plantear una reestructuración integral surge el "Nuevo bachillerato ecuatoriano" que, sobre el tema de esta investigación, menciona la intención de "conocer y valorar la dimensión humana de la sexualidad en toda su diversidad" ${ }^{88}$ En la propuesta de la comunidad educativa para el Plan nacional de educación 2016-2025 existe el interés de eliminar patrones de comportamiento discriminatorios y violentos y ampliar la atención para la salud sexual y reproductiva de adolescentes y zonas de mayor pobreza. ${ }^{89}$

84 República del Ecuador, Ministerio de Desarrollo Social, "Estrategia nacional intersectorial para la primera infancia", https://www.siteal.iiep.unesco.org/sites/default/files/sit_accion_files/siteal_ecuador_6005.pdf (acceso noviembre 28, 2020), 22.

85 República del Ecuador, Secretaría Nacional de Planificación y Desarrollo, Consejo Nacional de Igualdad de Género, Agenda nacional de las mujeres y la igualdad de género 2014-2017 (Quito: El Telégrafo, 2014), 70.

86 República del Ecuador, Constitución de la República (Quito: Registro Oficial núm. 449, 20 de octubre de 2008), art. 32.

87 República del Ecuador, Constitución de la República, art. 347, num. 6.

88 República del Ecuador, Ministerio de Educación, "Nuevo bachillerato ecuatoriano", https://www.siteal.iiep. unesco.org/sites/default/files/sit_accion_files/ec_0234.pdf (acceso septiembre 14, 2020), 31.

89 República del Ecuador, Ministerio de Educación, "Propuesta de la comunidad educativa para el Plan nacional de educación 2016-2025", http://www.siteal.iiep.unesco.org/sites/default/files/sit_accion_files/ siteal_ecuador_0240.pdf (acceso noviembre 28, 2020), 59. 
La Ley orgánica de salud aborda las responsabilidades del Ministerio de Salud Pública sobre el tema investigado, con la implementación de acciones de prevención en salud sexual, con énfasis en los adolescentes. ${ }^{90}$ Además, la Ley establece que el país:

[... elaborará políticas y programas educativos de implementación obligatoria en los establecimientos de educación a nivel nacional, para la difusión y orientación en materia de salud sexual y reproductiva, a fin de prevenir el embarazo en adolescentes, el VIH sida y otras afecciones de transmisión sexual, fomentar la paternidad y la maternidad responsables y erradicar la explotación sexual; asignará los recursos suficientes para ello. ${ }^{91}$

Los adolescentes que comentan de crímenes contra la integridad sexual y reproductiva serían obligados a participar en programas de educación sexual, como parte del tratamiento de las medidas socioeducativas. ${ }^{92}$

Por otro lado, el Reglamento General de la Ley orgánica de educación intercultural presenta directrices acerca de cómo actuar en caso de abuso sexual, pero solo de forma reactiva, pues no aborda la temática de la educación sexual preventiva. ${ }^{93}$ La Ley 175 establece la reeducación de agresores, pero, nuevamente, no trata la educación sexual como método preventivo. ${ }^{94}$ Está en vigor el Plan nacional de salud sexual y salud reproductiva 2007-2021, con el objetivo de desarrollar estrategias para modificar indicadores en la zona. ${ }^{95}$

Los mecanismos contra los enfoques sobre este tema tratan de interferir con las acciones llevadas a cabo por el Ministerio de Educación. Por ejemplo, en 2017, publicaciones de desinformación fueron difundidas en distintas redes sociales señalando que el Estado sugirió clases de educación sexual para que los estudiantes tuvieran "relaciones sexuales en todos los sentidos imaginables". Después de estas

90 República del Ecuador, Congreso Nacional, Ley 67 de 2006, "Ley orgánica de salud" (Quito: Registro Oficial núm. 423, 22 de diciembre de 2006).

91 República del Ecuador, Congreso Nacional, Ley 67 de 2006, art. 27.

92 República del Ecuador, Asamblea Nacional, Código orgánico integral penal (Quito: Registro Oficial núm. 180 , 10 de febrero de 2014), art. 385

93 República del Ecuador, Presidencia de la República, Decreto Ejecutivo 1241 de 2012, "Reglamento general a la Ley orgánica de educación intercultural” (Quito: Registro Oficial núm. 754, 26 de julio de 2012).

94 República del Ecuador, Asamblea Nacional, Ley s/n, "Ley orgánica integral para prevenir y erradicar la violencia contra las mujeres" (Quito: Registro Oficial núm. 175, 5 de febrero de 2018), art. 41.

95 República del Ecuador, Ministerio de Salud Pública, "Plan nacional de salud sexual y salud reproductiva 2017-2021", https://ecuador.unfpa.org/sites/default/files/pub-pdf/PLAN\%20NACIONAL\%20DE\%20SS\%20 Y\%20SR\%202017-2021.pdf (acceso noviembre 11, 2020). 
revelaciones, grupos conservadores hicieron manifestaciones en diferentes partes del país. El asunto fue desmentido por las autoridades locales. ${ }^{96}$

En 2020, la Corte Interamericana de Derechos Humanos declaró al Estado de Ecuador responsable por la violencia sexual sufrida por una adolescente de 14 años dentro de una escuela estatal, cometida por el vicerrector de la institución. El crimen tuvo relación con el suicidio de la joven. Este fue el primer episodio sobre violencia sexual contra una niña en ámbito educativo que conoció la Corte Interamericana. Su decisión indicó que los estudiantes tienen derecho a un entorno educativo seguro y libre de violencia sexual y resaltó la importancia del derecho a la educación sexual y reproductiva como parte del derecho a la educación. ${ }^{97}$

\section{Chile, Colombia y Ecuador en diálogo}

Mientras que Chile tiene desde hace diez años una ley de educación sexual obligatoria en la escuela secundaria y ya aborda en documentos la necesidad de anticipar esta enseñanza, Colombia y Ecuador discuten la cuestión en las leyes y planes gubernamentales, de modo que no está institucionalizada con el fin de aportar resultados directos. Si bien Colombia tiene como objetivo abarcar en los próximos años aproximadamente el 80 \% de las instituciones educativas con educación para la sexualidad, Ecuador todavía propone este enfoque mediante campañas informativas, sin llevarla a la escuela con un programa integral y continuo. La atención desigual explica las diferencias en la clasificación de embarazo adolescente en América Latina. Además, Chile es el más cercano a un método basado en las convenciones de derechos humanos: incluye la transversalidad en la enseñanza de la sexualidad, es decir, la asignatura se trata multilateralmente, donde los estudiantes se enfrentan a estos contenidos en diferentes oportunidades. Chile va aún más lejos, al prestar atención a la comunidad educativa transgénero, un tema que todavía aparece tímidamente en las convenciones. Así, trabaja con el objetivo de cambiar los patrones socioculturales, con propuestas para nuevos diseños educativos para la sexualidad, como plantea la OEA, por ejemplo.

Chile presenta los resultados de un número menor de adolescentes embarazadas y esta es una manera muy práctica de monitorear la efectividad de la educación

96 El Surtidor, "Las mentiras sobre laeducación sexual en América Latina”, Salud con lupa, Sec. Comprueba, 7 de diciembre de 2019, http://saludconlupa.com/comprueba/las-mentiras-sobre-la-educacion-sexual-en-america-latina

97 Corte Interamericana de Derechos Humanos, Caso Guzmán Albarracín y otras vs. Ecuador, Sentencia del 24 de junio de 2020. 
sexual. En otras palabras, la educación sobre sexualidad puede ser un pilar en la construcción de un país con más oportunidades para los grupos históricamente vulnerables, que, al igual que otros ciudadanos, tienen garantizados los derechos constitucionales y, por lo tanto, merecen atención del Estado. Lo interesante es que el país reconoce que todavía no hace lo suficiente y busca mejorar los métodos didácticos actuales, con el fin de reducir aún más las tasas de embarazo adolescente y también para hacer frente a los desafíos ya mencionados en este estudio.

En Colombia, la educación sexual está presente en leyes y es uno de los objetivos a alcanzar por la educación para los próximos años, incluso con un enfoque laico. Sin embargo, las iniciativas aisladas con muchos objetivos específicos y no plurales, como sucede en Chile, hacen que este tipo de enseñanza siga desmembrada, si hablamos de una educación sexual transversal. El mencionado caso del estudiante Sergio Urrego mostró a las instituciones educativas y administrativas que el modelo empleado hasta ahora en la sexualidad debe ampliarse y surgieron iniciativas con una educación orientada a los derechos humanos, sexuales y reproductivos, con un enfoque de género. Colombia está en el camino hacia mejores resultados en el número no solo del índice de embarazo adolescente, sino de una mejor relación de convivencia basada en la igualdad de género. No obstante, es necesario que la obra sea vista con una mirada estratégica. La alineación de la educación sexual con otras acciones planificadas y llevadas a cabo en los campos de la educación, la salud, del desarrollo social y económico y de los derechos humanos podría llevar al país a alcanzar los objetivos establecidos.

Las altas tasas de embarazo adolescente han hecho que Ecuador implemente en las leyes nacionales los intentos de reducir estas cifras y salir del tope de la clasificación en América Latina. Empero, el enfoque del tema no se hace sistemáticamente y se agrupan varios sectores del Estado; las iniciativas se centran, en la mayoría de los casos, en reducir el número de adolescentes embarazadas. Una educación sexual integral, aun sugerida por los organismos internacionales de derechos humanos, puede llevar al país a avanzar en más temas sociales y económicos. La decisión de la Corte Interamericana de Derechos Humanos contra Ecuador sienta un precedente histórico para todo el hemisferio, en especial para el propio país, que ve un importante caso de violación cometida por un agente del Estado, con el factor agravante de ser seguido por un suicidio, expuesto y juzgado internacionalmente. Si Ecuador busca no repetir el delito condenado es necesario revisar cómo siguen las recomendaciones cada vez más constantes en las convenciones internacionales. 


\section{Conclusión}

Al implementar leyes y programas de educación sexual en el país, es necesario estar atentos, como lo hace Chile, a los conceptos de transversalidad y hacer actualizaciones constantes, para que los resultados muestren avance y contribuyan a los conceptos de derechos humanos y desarrollo, personales y económicos, como lo propugnan las convenciones y los autores investigados. Estas características, ausentes en la realidad colombiana y ecuatoriana, determinan si tendrán repercusiones positivas.

La educación sexual aún no está lo suficientemente desarrollada en el marco de un sistema de políticas públicas de educación y salud. Por eso se requieren más estudios, para que este asunto sea visto no con una mirada ideológica o de adoctrinamiento, sino como una estrategia económica y de desarrollo. Una investigación segmentada por países, enfocada en los costos de aplicar un programa de educación sexual integral, contrastada con los beneficios que la actividad proporciona, sea en índices económicos o de desarrollo, puede traer ventajas de aplicabilidad más concretas. Además, las recomendaciones emitidas por los órganos de derechos humanos también pueden ser empleadas en ámbitos menores e inspirar políticas públicas de entidades territoriales o de escuelas específicas.

Esta investigación tomó como referente la tasa de adolescentes embarazadas en los países mencionados, pero también se podrían clasificar otros temas relacionados con la falta de educación sexual integral, como el suicidio, el feminicidio, los asesinatos contra la población LGBTQ+, la violencia motivada por prejuicios, el abuso sexual y la violación de niños, niñas y adolescentes, entre otros. La efectividad de las leyes en las escuelas desempeña un papel clave, al igual que las familias, en la identificación y asistencia a jóvenes vulnerables o perjudicados por la falta de información, teniendo en cuenta que el acceso a la información es también un derecho humano.

\section{Referencias}

Asamblea General de las Naciones Unidas. Convención de los derechos del niño. París, 20 de noviembre de 1989.

Asamblea General de las Naciones Unidas. Declaración universal de los derechos humanos. París, 10 de diciembre 1948. 
Asamblea General de las Naciones Unidas. International Covenant on Economic, Social and Cultural Rights. París, 16 de diciembre de 1966.

Astudillo Muñoz, María Nelcy. "La educación sexual en Latinoamérica: un campo de fuerzas en tensión". Cultura del cuidado 14, núm. 1 (2017): 57-70, https://doi. org/10.18041/1794-5232/cultrua.2017v14n1.4329 (acceso noviembre 27, 2020).

Bedoya Abella, Claudia Liliana. "Educación para la sexualidad y construcción de ciudadanía". Sophia 10, núm. 1 (2014): 95-106, https://www.redalyc.org/pdf/4137/413734078009. pdf (acceso mayo 1, 2021).

Bermúdez, Luis Miguel y Simón Granja Matías. Sexualidad sin pelos en la lengua. Bogotá: Intermedio, 2019.

Biblioteca del Congreso Nacional de Chile. "Historia de la Ley 20 418. Fija normas sobre información, orientación y prestaciones en materia de regulación de la fertilidad". http://www.codajic.org/sites/www.codajic.org/files/Historia\%20de\%20la\%20 Ley\%2020418.pdf (acceso diciembre 27, 2020).

Chade, Jamil. "Em manobra, Brasil lavará as mãos em ação de ultraconservadores na ONU”. UOL, Sec. Noticias, 16 de julio de 2020, https://noticias.uol.com.br/ colunas/jamil-chade/2020/07/16/em-manobra-brasil-lava-as-maos-em-acao-deultraconservadores-na-onu.htm

Corpe S. L., Francisco García Ruiz, José Carlos Cordero Pérez. Guardia civil. Volumen I: Escala de cabos y guardias. Temario. Sevilla: Rodio, 2020.

Corte Interamericana de Derechos Humanos. Caso Guzmán Albarracín y otras vs. Ecuador. Sentencia del 24 de junio de 2020.

Damico Figueiró, Mary Neide. "Educação sexual: como ensinar no espaço da escola". Linhas 7, núm. 1 (2006): 1-21, https://www.periodicos.udesc.br/index.php/linhas/ article/view/1323 (acceso julio 12, 2020).

DW. "ONU: El embarazo adolescente es una fábrica de pobres en América Latina". DW, Sec. América Latina, 4 de noviembre de 2004, http://www.dw.com/es/onu-elembarazo-adolescente-es-una-f\%C3\%Albrica-de-pobres-en-am\%C3\%A9ricalatina/a-55569024

El Surtidor. "Las mentiras sobre la educación sexual en América Latina". Salud con lupa, Sec. Comprueba, 7 de diciembre de 2019, https://saludconlupa.com/comprueba/ las-mentiras-sobre-la-educacion-sexual-en-america-latina

Fondo de Población de las Naciones Unidas [Unfpa]. "El impacto socioeconómico del embarazo en la adolescencia representa 1242 millones de dólares o 0,35 \% del PIB anual para seis países de América Latina”. http://lac.unfpa.org/es/news/el-impactosocioecon\%C3\%B3mico-del-embarazo-en-la-adolescencia-representa-1242-millonesde-d\%C3\%B3lares-o (acceso noviembre 15, 2020). 
Fondo de Población de las Naciones Unidas [Unfpa]. El poder de decidir. Derechos reproductivos y transición demográfica. Nueva York: Autor, 2018.

Frischeisen, Luiza Cristina. "Educação de gênero na escola previne feminicídio", https:// agenciabrasil.ebc.com.br/politica/noticia/2018-09/educacao-de-genero-na-escolaprevine-feminicidios-dizem-especialistas (acceso octubre 27, 2020).

Gesta Leal, Rogério y Clovis Gorczevski. "Artigo 13”" en Comentários ao Pacto internacional dos direitos econômicos, editado por Wagner Balera y Vladimir Oliveira da Silveira, 213-224. San Pablo: Classica, 2013.

Haddad Guarnieri, Tathiana. "Os direitos das mulheres no contexto internacional — da criação da ONU à Conferência de Beijing”. Revista Eletrônica da Faculdade Metodista Granbery, núm. 8 (2010): 1-28, http://re.granbery.edu.br/artigos/MzUx.pdf (acceso enero 24, 2021).

Hunt, Lynn. Inventing Human Rights: A History. Nueva York: W. W. Norton, 2007.

Instituto Colombiano de Bienestar Familiar. "Manual operativo. Modalidad institucional para la atención a la primera infancia”. https://www.siteal.iiep.unesco.org/sites/default/ files/sit_accion_files/co_3307_-manual_operativo_modalidad_institucional.pdf (acceso noviembre 11, 2020).

Londoño, María Ladi. Derechos sexuales y reproductivos: los más humanos de todos los derechos. Cali: Iseder, 1996.

Novak Talavera, Fabián. "La Declaración universal de derechos humanos cincuenta años después”. Agenda Internacional 4, núm. 10 (1998): 75-86, http://revistas.pucp.edu. pe/index.php/agendainternacional/article/view/7194 (acceso mayo 12, 2020).

Organización de las Naciones Unidas [ONU]. "Estados miembros". http://www.un.org/ es/member-states/index.html (acceso noviembre 13, 2020).

Organización de las Naciones Unidas [ONU]. Informe de la Conferencia internacional sobre la población y el desarrollo. El Cairo, 5 a 13 de septiembre de 1994. Nueva York: Autor, 1995. Organización de las Naciones Unidas [ONU]. Informe de la cuarta Conferencia mundial sobre la mujer. Beijing, 4 a 15 de septiembre de 1995. Nueva York: Autor, 1996.

Organización de las Naciones Unidas [ONU]. Informe del Consejo de Derechos Humanos. Nueva York: Autor, 2019.

Organización de las Naciones Unidas para la Educación, la Ciencia y la Cultura [Unesco]. International Technical Guidance on Sexuality Education: An Evidence-Informed Approach. París: Autor, 2018.

Organización de las Naciones Unidas para la Educación, la Ciencia y la Cultura [Unesco].

Orientaciones técnicas internacionales sobre educación en sexualidad. Santiago: Autor, 2010. Organización de los Estados Americanos [OEA], Comisión Interamericana de Derechos Humanos. Protocolo adicional a la Convención americana sobre derechos humanos en 
materia de derechos económicos, sociales, "Protocolo de San Salvador". El Salvador, 17 de noviembre de 1988.

Organización de los Estados Americanos [OEA]. Convención interamericana para prevenir, sancionar y erradicar la violencia contra la mujer (Convención de Belém do Pará). Belén, 9 de junio de 1994.

Pérez Prada, Mónica Patricia, Lizeth Cristina Martínez Baquero, Mildred Alexandra Vianchá Pinzón y Bertha Lucía Avendaño Prieto. "Intento e ideación suicida y su asociación con el abuso sexual en adolescentes escolarizados de Boyacá-Colombia”. Diversitas 13, núm. 1 (2017): 91-101, https://www.redalyc.org/pdf/679/67952833007.pdf (acceso noviembre 17, 2020).

Pineda Roa, Carlos Alejandro. "Factores asociados con riesgo de suicidio de adolescentes y jóvenes autoidentificados como lesbianas, gays y bisexuales: estado actual de la literatura". Revista Colombiana de Psiquiatría 48, núm. 1 (2017): 333-349, https://www. researchgate.net/publication/262878444_Factores_asociados_con_riesgo_de_suicidio_de_adolescentes_y_jovenes_autoidentificados_como_lesbianas_gays_y_bisexuales_estado_actual_de_la_literatura (acceso noviembre 17, 2020).

Red por los derechos de la infancia en México [Redim]. La desigualdad de género comienza en la infancia. Manual teórico-metodológico para transversalizar la perspectiva de género en la programación con enfoque sobre derechos de la infancia. Ciudad de México: Autor, 2016. República de Chile, Consejo Nacional de la Infancia. "Política nacional de niñez y adolescencia. Sistema integral de garantías de derechos de la niñez y adolescencia 2015-2025". http://www.siteal.iiep.unesco.org/sites/default/files/sit_accion_files/ siteal_chile_0654.pdf (acceso diciembre 11, 2020).

República de Chile, Junta Nacional de Jardines Infantiles. "Lineamientos técnicos. Marco pedagógico para la mejora de la calidad de las prácticas educativas". http://www. siteal.iiep.unesco.org/sites/default/files/sit_accion_files/6466.pdf (acceso diciembre 11, 2020).

República de Chile, Ministerio de Educación, Ministerio de Salud y Ministerio de la Mujer y la Equidad de Género. "Educación sexual: estrategia en sexualidad, afectividad y género". http://www.siteal.iiep.unesco.org/sites/default/files/sit_accion_files/6457. pdf (acceso diciembre 2, 2020).

República de Chile, Ministerio de Educación, Unidad de Equidad de Género. "Educación para la igualdad de género. Plan 2015-2018". https://www.siteal.iiep.unesco.org/ sites/default/files/sit_accion_files/siteal_chile_0652.pdf (acceso agosto 10, 2020).

República de Chile, Ministerio de Educación. "Bases curriculares de la educación parvularia". https://www.siteal.iiep.unesco.org/sites/default/files/sit_accion_files/6461.pdf (acceso agosto 8, 2020). 
República de Chile, Ministerio de Educación. "Modelo de gestión intersectorial. Aulas del bien estar". https://www.siteal.iiep.unesco.org/sites/default/files/sit_accion_files/6424. pdf (acceso agosto 18, 2020).

República de Chile, Ministerio de Educación. "Objetivos fundamentales y contenidos mínimos obligatorios de la educación básica y media”. https://www.siteal.iiep.unesco.org/ sites/default/files/sit_accion_files/siteal_chile_0636.pdf (acceso agosto 14, 2020).

República de Chile, Ministerio de Justicia y Derechos Humanos, Servicio Nacional de Menores. "Orientaciones técnicas para concurso de proyectos. Programa de protección especializada en reinserción educativa". http://www.siteal.iiep.unesco.org/sites/ default/files/sit_accion_files/6451.pdf (acceso diciembre 27, 2020).

República de Chile, Ministerio de la Mujer y la Equidad de Género. "Cuarto plan nacional de igualdad entre mujeres y hombres 2018-2030". http://www.siteal.iiep.unesco. org/sites/default/files/sit_accion_files/ch_8001.pdf (acceso diciembre 11, 2020). República de Colombia, Congreso de la República. Ley 1098 de 2006, "Por la cual se expide el Código de la infancia y la adolescencia”. Bogotá: Diario Oficial núm. 46 446, 8 de noviembre de 2006.

República de Colombia, Congreso de la República. Ley 115 de 1994, "Por la cual se expide la Ley general de educación”. Bogotá: Diario Oficial núm. 41 214, 8 de febrero de 1994. República de Colombia, Congreso de la República. Ley 1620 de 2013, "Por la cual se crea el Sistema nacional de convivencia escolar y formación para el ejercicio de los derechos humanos, la educación para la sexualidad y la prevención y mitigación de la violencia escolar". Bogotá: Diario Oficial núm. 48 733, 15 de marzo de 2013. República de Colombia, Consejo Nacional de Política Económica y Social. "Documento Conpes Social núm. 147/2012. Lineamientos para el desarrollo de una estrategia para la prevención del embarazo en la adolescencia y la promoción de proyectos de vida para los niños, niñas, adolescentes y jóvenes en edades entre 6 y 19 años". http://www.siteal.iiep.unesco.org/sites/default/files/sit_accion_files/co_0413.pdf (acceso diciembre 22, 2020).

República de Colombia, Departamento Nacional de Planeación. Bases del Plan nacional de desarrollo 2018-2022. Bogotá: Grupo de Comunicaciones DNP, 2018.

República de Colombia, Ministerio de Salud. "Política nacional de sexualidad, derechos sexuales y derechos reproductivos". http://www.siteal.iiep.unesco.org/sites/default/ files/sit_accion_files/3302.pdf (acceso diciembre 11, 2020).

República del Ecuador, Asamblea Nacional. Código orgánico integral penal. Quito: Registro Oficial núm. 180, 10 de febrero de 2014.

República del Ecuador, Asamblea Nacional. Ley s/n, "Ley orgánica integral para prevenir y erradicar la violencia contra las mujeres". Quito: Registro Oficial núm. 175, 5 de febrero de 2018. 
República del Ecuador, Congreso Nacional. Ley 67 de 2006, "Ley orgánica de salud". Quito: Registro Oficial núm. 423, 22 de diciembre de 2006.

República del Ecuador, Consejo Nacional de Planificación. Toda una vida. Plan nacional de desarrollo 2017-2021. Quito: Senplades, 2017.

República del Ecuador, Gobierno Nacional. "Pacto del gobierno nacional con niños, niñas y adolescentes contra la violencia”. https://www.siteal.iiep.unesco.org/sites/ default/files/sit_accion_files/ec_6130.pdf (acceso septiembre 18, 2020).

República del Ecuador, Ministerio de Desarrollo Social. "Estrategia nacional intersectorial para la primera infancia". http://www.siteal.iiep.unesco.org/sites/default/files/ sit_accion_files/siteal_ecuador_6005.pdf (acceso noviembre 28, 2020).

República del Ecuador, Ministerio de Educación y Cultura. "Plan decenal de educación del Ecuador 2006-2015". http://www.siteal.iiep.unesco.org/sites/ default/files/sit_accion_files/ec_9029.pdf (acceso noviembre 28, 2020).

República del Ecuador, Ministerio de Educación. "Nuevo bachillerato ecuatoriano". https:// www.siteal.iiep.unesco.org/sites/default/files/sit_accion_files/ec_0234.pdf (acceso septiembre 14, 2020).

República del Ecuador, Ministerio de Educación. "Propuesta de la comunidad educativa para el Plan nacional de educación 2016-2025”. http://www.siteal.iiep.unesco.org/sites/ default/files/sit_accion_files/siteal_ecuador_0240.pdf (acceso noviembre 28, 2020).

República del Ecuador, Ministerio de Salud Pública. "Plan nacional de salud sexual y salud reproductiva 2017-2021". http://ecuador.unfpa.org/sites/default/files/ pub-pdf/PLAN\%20NACIONAL\%20DE\%20SS\%20Y\%20SR\%202017-2021.pdf (acceso noviembre 11, 2020).

República del Ecuador, Movimiento Alianza País. "Programa de Gobierno 2017-2021". http:// www.siteal.iiep.unesco.org/sites/default/files/sit_accion_files/siteal_ecuador_0243. pdf (acceso noviembre 28, 2020).

República del Ecuador, Presidencia de la República. Decreto Ejecutivo 1241 de 2012, "Reglamento general a la Ley orgánica de educación intercultural". Quito: Registro Oficial núm. 754, 26 de julio de 2012.

República del Ecuador, Secretaría Nacional de Planificación y Desarrollo, Consejo Nacional de Igualdad de Género. Agenda nacional de las mujeres y la igualdad de género 2014-2017. Quito: El Telégrafo, 2014.

República del Ecuador. Constitución de la República. Quito: Registro Oficial núm. 449, 20 de octubre de 2008.

Tôrres, Lara. "Educação sexual nas escolas e a prevenção em caso de abuso". Leia Já, Sec. Educação, 31 de agosto de 2019, https://www.leiaja.com/carreiras/2020/08/31/ educacao-sexual-nas-escolas-e-prevencao-em-caso-de-abuso 
Uchôa Barbosa, Luciana, Cátia Silene Carrazoni Lopes Viçosa y Vanderlei Folmer. "A educação sexual nos documentos das políticas de educação e suas ressignificações". Acervo Saúde 11, núm. 10 (2019): 1-10, https://doi.org/10.25248/reas.e772.2019 (acceso julio 12, 2020). 